\title{
Potential health dangers of new invasive species similar to indigenous plants that are used as food or medicine--an example from Bangladesh
}

By

Salma Hossain, Department of Environmental Science, Gono Bishwabidyalay, Savar, Dhaka 1344, Bangladesh [Salma.Zuberi.Runu@gmail.com] ,

Rozina Parul, Department of Pharmacy, Gono Bishwabidyalay, Savar, Dhaka 1344, Bangladesh

[rozina.parul@gmail.com]

M.I. Zuberi, Department of Environmental Science, Gono Bishwabidyalay, Savar, Dhaka 1344, Bangladesh [iqbal.zuberi@gmail.com] 


\section{Abstract}

About 20,000 herbal products are currently available on the global market, and medicinal plants' annual trade turnover is approximately US \$ 4 billion in the United States alone. As climate change starts increasingly interfering with monoculture grown crops--and this will likely be more serious more quickly in tropical areas--wild foods may become increasingly lifesaving. But at the same time, invasive plants will likely also spread more rapidly. Centella asiatica (L.) Urb, (Indian Pennywort) has been widely used from the wild (also cultivated and marketed in Bangladesh, China, Southeast Asia, India, Sri Lanka), the leaves eaten as a component of mixed green vegetable, pot herb and is also an important item in the traditional medicine systems. In Bangladesh it is widely used as a health food and in the folk and traditional system of medicine for improving memory and for the treatment of a variety of ailments. Market surveys have detected two different species, $C$, erecta and $C$. verticillata, wrongly identified as the exotic species, Indian Pennywort because of their morphological similarity. Comparison of taxonomic and pharmaceutical characteristics among these species indicated a wide difference and this misidentification might pose a health risk to the consumers, the edibility and safety of the two exotic species being unknown. Public health nutritionists need to work with experts in plant taxonomy to identify and attempt to reduce the risk of invasive species of plants that may be poisonous and are similar in appearance to indigenous plants that are used for food or medicine.

Key words: Medicinal plants, Identification, Centella, Indian Pennywort, Bangladesh

\section{Introduction}

About 20,000 herbal products are currently available on the global market, and medicinal plants' annual trade turnover is approximately US \$ 4 billion in the United States alone (Buck and Michel, 2000). Wild greens which have been proved palatable and apparently safe down through history are consumed globally, particularly in the poverty prone areas and during food shortages. Many of these are also used medicinally to treat a wide variety of ailments and as sources of minerals and vitamins. However, some of these species may possess minimal toxicity, and some contain toxic ingredients that may not yet be identified. 
Centella asiatica, a popular ingredient in various herbal products on the global market is known to contain pentacyclic triterpene glycosides in abundance. One ingredient, Asiaticoside, is considered to contribute in the pharmaceutical effects of $C$. asiatica and is widely used for wound healing (Gohil,et al,2010; Orhan, 2012; Bylka et al.,2014), as a “blood purifier” as well as for treating high blood pressure, for memory enhancement and promoting longevity (Ponnusamy et al., 2008; Hussin et al.,2009). The plant is also important for its high content of medicinally important triterpenoids and beneficial carotenoids, vitamins B and C, proteins, important minerals, and phytonutrients such as flavonoids, volatile oils, tannins, and polyphenol (Randriamampionona et al, 2007; Gamage et al, 2015). The immature leaves are commonly eaten raw as a salad, cooked as a soup, or mixed with other wild green vegetables (Reddy et al, 2007; Rahman, 2013; Khatun et al, 2013; Thongam et al, 2016), and the juice of fresh leaves is prescribed in traditional medicine (Gohil et al, 2010; Bhawmik et al., 2016).

Centella is known to occur in distinct 'morphotypes' with differences in morphological characteristics, eg, leaf shape, the length of lamina and petiole as well as inflorescence structure and have been shown to differ genetically (Schubert and van Wyk, 1997; Prasad et al, 2014). Interestingly, in the local markets around Dhaka (capital city of Bangladesh), a number of samples were seen to be sold as C. asiatica even though they did not appear to be so. Samples collected from Mirpur, Savar, Ganda, and Islampur markets and the GK Savar Campus were examined morphologically and taxonomically to verify their correct taxonomic identity. Of the three 'morphotypes' shown in Fig 1, Samples 1b and 1c were only available in markets and nurseries but were not found in the wild like the Sample (1a) which was identified as C. asiatica, suggesting that the other two (Fig $1 \mathrm{~b}$ and c) were not indigenous to Bangladesh.

As morphological characters, genetic identity and chemical contents can play important roles in the accurate identification, proper safety and quality evaluation of medicinal plants (Bhattacharyya et al., 2015), this report aimed at providing evidence that these two are not $C$. asiatica. 


\section{Materials and methods}

Plant samples were collected from local markets and from fields around Savar, Dhaka and were used for morphological/anatomical examination using standard methods and equipment and standard pharmaceutical analysis.

\section{Results and Discussion}

\section{Morphological differences}

Centella asiatica is a clonal, perennial herbaceous creeper commonly found throughout Bangladesh growing in crop fields, fallow lands and moist places (Fig 1a), with small fan-shaped green leaves and white or light purple-to-pink flowers and small oval fruits. While $C$. verticillata, also a perennial, glabrous, creeping plant with slender stems (Fig. 1b); round leaves and cream-colored flowers was noted to be native to North and South America (Mathias, 1936; Wagner et al., 1990). There has been one report of this species now growing in Bangladesh (Khatun et al 2010). The third sample, Centella erecta, a very closely related species, is also found in North and South America (Fig 1c). The stolon and stem of C. erecta were deeply embedded in the soil, whereas the stems of C. asiatica and C. verticillata, grow near the surface. Other morphological features of the leaf (leaf size, surface area, number of dentate or crenate and length of leaf petiole) were helpful in differentiating these species (Table 1).

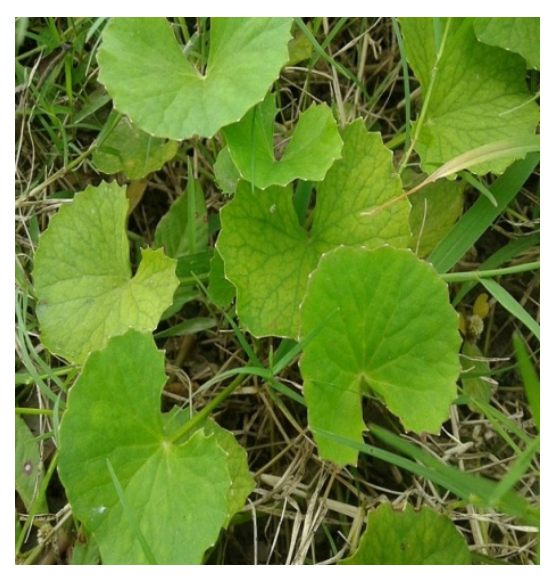

Fig 1 a Centella asiatica 

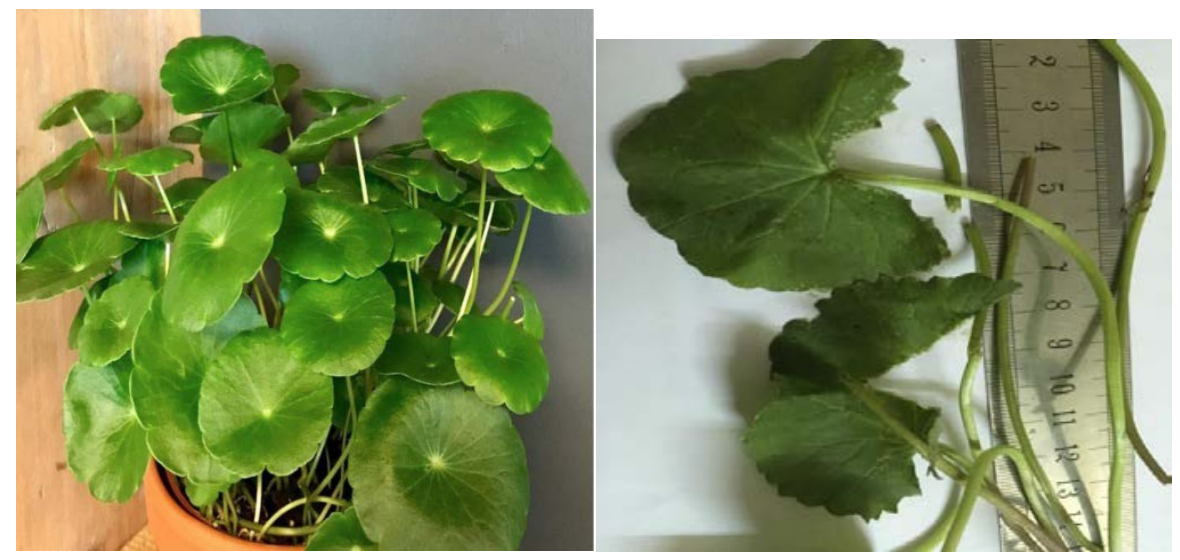

Fig 1 b Centella verticillata Fig 1 c Centella erecta

Fig 1 Morphological characters of the three species of Centella

The stem of $C$. erecta displayed a thick and hard texture compared to $C$. asiatica and $C$. verticillata, which were thin and fragile. The leaves of C. asiatica were smaller in size (11.9016.92, $\left.\mathrm{cm}^{2}\right)$ than Centella verticillata or C. erecta $\left(22.40-42.20, \mathrm{~cm}^{2}\right)$ and had a cordate blade shape which was more dentate or crenate in leaf margin, while C. erecta had reniform-shaped leaves with smooth-glossy texture and little dentate in the margin. Measurements of leaf characters (leaf area, blade length, petiole length) are presented in Table 1.

Table 1. Comparisons of leaf characteristics of the three species of Centella.

\begin{tabular}{|l|c|c|c|}
\hline Species & Leaf surface area $\left(\mathrm{cm}^{2}\right)$ & Leaf blade length $(\mathrm{cm})$ & $\begin{array}{l}\text { Length of leaf petiole } \\
(\mathrm{cm})\end{array}$ \\
\hline C. asiatica & $6.78-7.11$ & $1.79-1.99$ & $12.70-16.20$ \\
\hline C. verticillata & $15.58-21.43$ & $2.98-4.05$ & $18.09-20.65$ \\
\hline C. erecta & $30.09-34.24$ & $4.92-5.45$ & $23.99-25.42$ \\
\hline
\end{tabular}

\section{Pharmaceutical comparisons}

For pharmaceutical comparisons, enough plant materials were obtained for only two species, $C$. asiatica and C. verticillata. The freshly prepared crude extract was qualitatively tested for the identification of chemical constituents, such as, alkaloids, flavonoids, steroids, glycosides, saponins, terpenoids, gums and tannins. 
World Nutrition 2018;9(3):163-175

Table 2 Results of Qualitative analysis of Phytochemicals for Centella species

\begin{tabular}{|c|c|c|}
\hline \multirow{2}{*}{ Test } & \multicolumn{2}{|c|}{ Methanol Extracts } \\
\hline Alkaloids & - & Centella venticillata \\
\hline Carbohydrate & - & - \\
\hline Flavonoids & - & - \\
\hline Glycosides & + & - \\
\hline Phenolic compounds & + & - \\
\hline Protein & + & - \\
\hline Quinones & + & + \\
\hline Saponins & + & - \\
\hline Terpenoide & - & - \\
\hline Tanin & + & + \\
\hline
\end{tabular}

+ indicates high and - indicates low levels

Differences found between the two Centella species were that glycosides, quinones, and phenolic compounds were present only in Centella asiatica.

A DPPH (2,2-diphenyl-1-picrylhydrazyl) Free Radical Scavenging Assay (Mazumder and Rahman, 2008) was carried out, results given in Table 3.

Table 3. DPPH Free Radical Scavenging Assay of the two Centella species

\begin{tabular}{|l|l|}
\hline Name of sample & $\mathrm{IC}_{50}(\mu \mathrm{g} / \mathrm{ml})$ \\
\hline Ascorbic Acid Standard & 70.3 \\
\hline C. asiatica & 617.6 \\
\hline C. verticillata & 482.3 \\
\hline
\end{tabular}

The $\mathrm{IC}_{50}$ values of the methanolic extracts of C. asiatica, C. verticillata were $617.6 \mu \mathrm{g} / \mathrm{ml}$ and $482.3 \mu \mathrm{g} / \mathrm{ml}$ respectively which were much higher than the ascorbic acid standard (70.3) showing a difference between the two species. The percentage Scavenging Activity of methanolic extract of C. asiatica and C. verticellata given in Table 4 show that the methanol extract of the plant samples exhibited good antioxidant potency ( $\mathrm{IC}_{50}=6.67 \mu \mathrm{g} / \mathrm{ml}$ and $\mathrm{IC}_{50}=25.5 \mu \mathrm{g} / \mathrm{ml}$ ) respectively, 
World Nutrition 2018;9(3):163-175

which was close to the antioxidant effect of ascorbic acid ( $\left.\mathrm{IC}_{50}=7.5 \mu \mathrm{g} / \mathrm{ml}\right)$. The presence of phenols and flavonoid in the plant extracts may be a reason for this DPPH-scavenging activity.

Table 4. Percentage Scavenging Activity of the two Centella species

\begin{tabular}{|c|c|c|c|}
\hline Concentration & $\begin{array}{l}\text { \% Scavenging } \\
\text { of C. asiatica }\end{array}$ & $\begin{array}{l}\text { \% Scavenging of } \\
\text { C. verticillata }\end{array}$ & $\begin{array}{c}\text { \% Scavenging of } \\
\text { Ascorbic Acid }\end{array}$ \\
\hline 25 & 31.01 & 32.21 & 36.43 \\
\hline 50 & 32.04 & 34.45 & 45.22 \\
\hline 100 & 32.90 & 34.80 & 54.09 \\
\hline 200 & 35.49 & 41.60 & 62.88 \\
\hline 400 & 41.69 & 49.10 & 71.66 \\
\hline 800 & 55.73 & 62.27 & 89.06 \\
\hline
\end{tabular}

Total phenolic contents of the methanolic extracts of $C$. asiatica and C. verticillata were determined by using the Folin-Ciocalteu reagent and were expressed as Gallic Acid Equivalents (GAE) per gram of plant extract. Phenolics might be important components as anti-oxidants. Methanolic extracts contained considerable amounts of phenolic compounds $(40.5 \mu \mathrm{g} / \mathrm{ml}$ in $C$. asiatica and $23.0 \mu \mathrm{g} / \mathrm{ml}$ in C.verticillata).

There are widely reported genetic and pharmaceutical differences too, the genetic diversity parameters calculated based on the Inter Simple Sequence Repeat (ISSR) polymorphism and Thin Layer Chromatography saponin profiles showed C. asiatica is distinctly different from $C$. erecta (Ali et al, 2017). Also, C. erecta exhibited lower total phenolic content than C. asiatica ( $p$ $<0.05$ ) and the overall results showed that the C. erecta methanolic extract had significantly lower total saponin content than C. asiatica (Ali et al. 2017). The High-Performance Liquid Chromatography (HPLC) quantification of the target triterpene and phenolic compounds indicated that average content of madecassoside, total triterpenes and chlorogenic acid in $C$. erecta were significantly lower than C. asiatica. Also kaempferol and its derivatives were reported in C. asiatica (Maulidiani et al., 2012, 2014) but there is no reports of these compounds in C. erecta (Ali et al 2017). The colorimetric determination and the total content of the four triterpene glycosides and aglycones (asiaticoside, madecassoside, asiatic acid and madecassic 
World Nutrition 2018;9(3):163-175

acid) obtained by HPLC- photodiode array (PDA) analysis indicated that C. erecta samples had the lowest content of total saponins and sapogenins compared to C. asiatica (Ali et al 2017)

\section{Discussion}

Though herbal and traditional medicines are often known to have fewer side effects in comparison with synthetic drugs, certain medicinal plants may cause acute poisoning incidents in children, sick or elderly (Wojcikowsk et al, 2004; Gill and Rieder, 2008; Phua et al. 2009; Asif, 2012; Malangu, 2014: Ghorani-Azam et al.2018; Philip Stark et al 2018). In a review, Malangu (2014) screened a total of 127 articles with 1453 intoxicated cases showing that some medicinal plants can cause acute poisoning and complications.

The morphological and pharmaceutical evidence suggests that C. erecta and C.verticillata are different from C.asiatica - a plant species used in many countries as a source of nutrition and medical cure. As the edibility of $C$, verticillata and C. erecta is unknown, a search in the PubMed Website, using the botanical names of the two plants landed with 626 hits for $C$. asiatica but only 4 hits for C. verticillata (Nature Weekly 2017). Though C.erecta has been included in the Guide book 'WILD EDIBLE PLANTS OF TEXAS' (https://medivetus.com/botanic/wild-edible-plants-of-texas-a-pocket-guide-to-the-identificationcollection-preparation-and-use-of-60-wild-plants-of-the-lone-star-state/), there is no authentic report on its safe edibility.

The fact that the two species, $C$, erecta and $C$. verticillata are not indigenous (apparently being introduced mistakenly as C. asiatica) to South and Southeast Asia, may also have long-term ecological risks (Pacific Island Ecosystems at Risk, 2013a, b). Many of the Centella species have been proved to become a potential threat to indigenous species because of their invasiveness and vigorous vegetative as well as sexual reproduction. Confusioni with $C$. asiatica is probably the reason for the widespread planting of $C$, verticillata in Singapre (Reuben et al, 2014). A Weed Risk Assessment was performed, and a score of 20 was obtained for $C$, verticillata (the high-risk threshold for aquatic plants is 19), indicating it as a high-risk species. It was already recommended for Invasive Alien Species status in Singapore with a high risk of naturalising and also recommended more stringent measures for the cultivation of this species in that region (Reuben et al, 2014). For Bangladesh the same risk exits. 
Centella asiatica is one of the most prominent marketed food supplements and medicinal herbs in the traditional systems of medicine in Indian, African and Chinese medicine (Brinkhaus et al 2000). The need for quality control has been envisaged by many international regulatory agencies and reflected in their guidelines to ensure safe use of natural products, food supplements, or botanical medicines (WHO, 2007; Speijers et al, 2010). However, chances of wrong identification remain and may create serious problems for food safety.

Public health nutritionists need to work with experts in the agricultural field to identify and attempt to reduce the risk of invasive species of plants that may be poisonous and are similar in appearance to indigenous plants that are used for food or medicine.

\section{Acknowledgement}

This research was funded by the Research Cell of Gono Bishwabidyalay which is gratefully acknowledged. 


\section{References}

Ali Alqahtani, Jun-Lae Cho, Ka Ho Wong, Kong M. Li, Valentina Razmovski-Naumovski,and George Q. Li1. 2017. Differentiation of Three Centella Species in Australia as Inferred from Morphological Characteristics, ISSR Molecular Fingerprinting and Phytochemical

CompositionFront Plant Sci. 2017; 8: 1980._doi: 10.3389/fpls.2017.01980

Asif M. 2012. A brief study of toxic effects of some medicinal herbs on kidney. Adv Biomed Res. 1:44.

Bhattacharyya P., Kumaria S., Tandon P. (2015). Applicability of ISSR and DAMD markers for phyto-molecular characterization and association with some important biochemical traits of Dendrobium nobile, an endangered medicinal orchid. Phytochemistry 117, 306-316. 10.1016/j.phytochem.2015.06.022

Bhowmik, S, Runa Akter Chowdhury, Md Aftab Uddin. 2016. Microbiological analysis and detection of anti-bacterial activity of Centella asiatica and Aloe vera samples collected from different areas of Dhaka city, Bangladesh Stamford Journal of Microbiology, Vol.6(1): 39-43.

Brinkhaus B, Lindner M, Schuppan D, Hahn EG. 2000. Chemical, pharmacological and clinical profile of the East Asian medical plant Centella asiatica. Phytomedicine. 7:427-48.

Buck M.L, Michel R.S. 2000.Talking with families about herbal therapies. J Pediatr;136:673-8.

Bylka W., Znajdek-Awizen P., Studzinska-Sroka E., Danczak-Pazdrowska A., Brzezinska M. 2014. Centella asiatica in dermatology: an Overview. Phytother. Res. 28, 1117-1124.

Gamage, C.U, Amila Saman. 2015. Gotu Kola (Centella asiatica): Nutritional Properties and Plausible Health Benefits. Advances in food and nutrition research 76. 137- 169 
World Nutrition 2018;9(3):163-175

Gill SK, Rieder MJ. 2008. Toxicity of a traditional Chinese medicine, Ganoderma lucidum, in children with cancer. Can J Clin Pharmacol. 15:e275-85.

Gorani-Azam A, S. Sepahi, B. Riahi-Zanjani, A. A. Ghamsari,S.A. Mohajeri, and M. BalaliMood. 2018. Plant toxins and acute medicinal plant poisoning in children: A systematic literature review. J Res Med Sci. 2018; 23: 26

Gohil,K.J. J. A. Patel, and A. K. Gajjar. 2010. Pharmacological Review on Centella asiatica: A Potential Herbal Cure-all,” Indian J Pharm Sci., 72(5), 546-56.

Hussin M., Hamid A. A., Mohamad S., Saari N., Bakar F., Dek S. P. 2009. Modulation of lipid metabolism by Centella asiatica in oxidative stress rats. J. Food Sci. 74, H72-H78.

Khatun, B. M. R., M. O. Rahman \& S. S. Sultana. 2010. Hydrocotyle verticillata Thunb. (Apiaceae)-a new angiospermic record for Bangladesh. Bangladesh Journal of Plant Taxonomy, 17: $105-108$.

Khatun M, Md. Abul Hassan, Shaikh Nazrul Islam, M. Oliur Rahman. 2013. Taxonomy of the leafy vegetables in Bangladesh. Bangladesh J. Plant Taxon. 20(1): 95-123

Malangu N. 2014.Contribution of plants and traditional medicines to the disparities and similarities in acute poisoning incidents in Botswana, South Africa and Uganda. Afr J Tradit Complement Altern Med. 11:425-38.

Maulidiani H., Khatib A., Shaari K., Abas F., Shitan M., Kneer R., et al. 2012. Discrimination of three Pegaga (Centella) varieties and determination of growth-lighting effects on metabolites content based on the chemometry of $1 \mathrm{H}$ nuclear magnetic resonance spectroscopy. J. Agric. Food Chem. 60, 410-417.

Maulidiani F., Khatib A., Shaari K., Lajis N. H. 2014. Chemical characterization and antioxidant activity of three medicinal Apiaceae species. Ind. Crops Prod. 55, 238-247. 
World Nutrition 2018;9(3):163-175

Nature Weekly. 2017. Short Notes on Nature Singapore. Asiatic Pennywort | Centella asiatica | http://www.natureloveyou.sg/Plant\%20Story/Note\%202017/27Weekly\%20Note\%2020172jul17.html

Orhan I. E. 2012. Centella asiatica (L.) Urban: from traditional medicine to modern medicine with neuroprotective potential. Evid. Based Complement. Alternat. Med. 2012:946259. $10.1155 / 2012 / 946259$

Pacific Island Ecosystems at Risk. 2013a. Hydrocotyle bonariensis (PIER Species Info). Pacific Island Ecosystems at Risk (PIER), US Forest Service.

[http://www.hear.org/pier/species/hydrocotyle_bonariensis.htm.]

Pacific Island Ecosystems at Risk. 2013b. Hydrocotyle ranunculoides (PIER Species Info). Pacific Island Ecosystems at Risk (PIER), US Forest Service. [http://www.hear.org/pier/species/hydrocotyle_ranunculoides.htm]

Philip Stark, Daphne Miller, Thomas Carlson, Kristen Rasmussen de Vasquez. 2018. OpenSource Food: Nutrition, Toxicology, and Availability of Wild Edible Greens in the East Bay. https://www.biorxiv.org/content/early/2018/08/06/385864

Phua DH, Zosel A, Heard K. 2009. Dietary supplements and herbal medicine toxicities-when to anticipate them and how to manage them. Int J Emerg Med. 2:69-76.

Ponnusamy K., Mohan M., Nagaraja H. S. 2008. Protective antioxidant effect of Centella asiaticabioflavonoids on lead acetate induced neurotoxicity. Med. J. Malaysia 63 (Suppl. A):102

Prasad A, Dhawan SS, Mathur AK, Prakash O, Gupta MM, Verma RK, Lal RK, Mathur A. 2014. Morphological, chemical and molecular characterization of Centella asiatica germplasms for commercial cultivation in the Indo-Gangetic plains. Nat Prod Commun. 2014 Jun; 9(6):77984. 
World Nutrition 2018;9(3):163-175

Rahman, M.O. 2013. Taxonomy of the leafy vegetables in Bangladesh. Bangladesh journal of plant taxonomy 20(1):95-123

Randriamampionona D, Diallo B, Rakotoniriana F, Rabemanantsoa C, Cheuk K, Corbisier AM, Mahillon J, Ratsimamanga S, El Jaziri M .2007. Comparative analysis of active constituents in Centella asiatica samples from Madagascar: application for ex situ conservation and clonal propagation. Fitoterapia. Dec; 78(7-8):482-9.

Reuben C. J. Lim, Alex T. K. Yee , Xin Yi Ng and Hugh T. W. Tan. 2014. Whorled Pennywort, Hydrocotyle Verticillata Thunb. (Araliaceae), A New Record of a Casual Aquatic Macrophyte in Singapore. Nature In Singapore 2014 7: 79-91

Reddy, K.N, Chiranjibi Pattanaik, C S Reddy \& V S Raju. 2007. Traditional knowledge on wild food plants in Andhra Pradesh Indian Journal of Traditional Knowledge. 6(1). 223-229.

Schubert M. T. R., van Wyk B.-E. 1997. A revision of Centellaseries Capenses (Apiaceae). Nord. J. Bot. 17, 301-314. 10.1111/j.1756-1051.1997 tb00318.x

Speijers G, Bottex B, Dusemund B, Lugasi A, Tóth J, Amberg-Müller J, et al. 2010. Safety assessment of botanicals and botanical preparations used as ingredients in food supplements: Testing a European food safety authority-tiered approach. Mol Nutr Food Res.54:175-85

Thongam B, Surjata Konsam, and Arun Kumar Handique. 2016. Assessment of wild leafy vegetables traditionally consumed by the ethnic communities of Manipur, northeast India J Ethnobiol Ethnomed. 2016; 12: 9.

WHO. 2007. WHO guidelines for assessing quality of herbal medicines with reference to contaminants and residues, World Health Organization, Geneva, 2007.

Wojcikowski K, Johnson DW, Gobé G. 2004. Medicinal herbal extracts-renal friend or foe. Part one: The toxicities of medicinal herbs? Nephrology (Carlton);9:313-8. 